\title{
Predictors of Mortality Among Children Co-Infected with Tuberculosis and Human Immunodeficiency Virus in Region, North Ethiopia, Retrospective Follow- Up Study
}

\author{
Jemberu Nigussie $^{1 *}$, Mekuria Kassa ${ }^{2}$, Goitom Halefom ${ }^{3}$, Haven Hadush ${ }^{2}$ and Bekahegn Grima ${ }^{1}$ \\ ${ }^{1}$ Department of Nursing, College of Health Science and Medicine, Dilla University, Ethiopia \\ ${ }^{2}$ School of Nursing, College of Health Sciences, Mekelle University, Ethiopia \\ ${ }^{3}$ School of Public Health, College of Health Sciences, Mekelle University, Ethiopia
}

*Corresponding author: Jemberu Nigussie, Department of Nursing, College of Health Science and Medicine, Dilla University, Ethiopia

ARTICLE INFO

Received: August 26, 2021

Published: September 30, 2021

Citation: Jemberu Nigussie, Mekuria Kassa, Goitom Halefom, Haven Hadush, Bekahegn Grima. Predictors of Mortality Among Children Co-Infected with Tuberculosis and Human Immunodeficiency Virus in Region, North Ethiopia, Retrospective Follow-Up Study. Biomed J Sci \& Tech Res 39(1)-2021. BJSTR. MS.ID.006252.

Abbreviations: AIDS: Acquired Immune Deficiency Syndrome; AHR: Adjusted Risk Ratio; CHR: Crude Risk Ratio; ART: Anti-Retroviral Therapy; CI: Confidence Interval; CPT: Co-Trimoxazole Preventive Therapy; ART: Anti-Retroviral Therapy; HGB: Hemoglobin; HIV: Human Immunodeficiency Virus; EPTB: Extrapulmonary Tuberculosis; PTB: Lung Tuberculosis; IPT: Isoniazid Preventive Therapy; OI: Opportunistic Infections; PLHIV: People Living With HIV; TB: Tuberculosis; TB and HIV: Tuberculosis And Human Immunodeficiency Virus; WHO: World Health Organizations

\begin{abstract}
Background: Tuberculosis (TB) and human immunodeficiency virus (HIV) coinfection in the human body potentiate each other by weakening the immune system and causing death, if untreated. Tuberculosis is a major cause of morbidity and mortality in children infected with the human immunodeficiency virus. Evidence on survival and predictors of mortality among TB and HIV co-infection in children is limited and not well documented in Ethiopia. This study aimed to evaluate the predictors of mortality among children with TB and HIV co-infected in general hospitals in two zones of the Tigray region, North Ethiopia, from 2008-2018.
\end{abstract}

Methods: An institution-based retrospective follow-up study was conducted. Data were collected from medical records using a data extraction checklist and then entered using epi-data manager 4.4.2.1 and then exported to STATA version 14 for analysis. The Cox regression model was used for both bivariate and multivariate analyses.

Results: Of a total of 253 children included in the analysis, 38(15\%) children have died. The overall mortality rate was 0.17 (95\% CI: $0.12,0.23$ ) per 1000 childmonth observation. Underweight at baseline (AHR=7.9 (95\% CI: 1.3, 49.3)), IPT non user (AHR=3.7; 95\%CI: 1.3-10.8), Poor adherence to ART (AHR = 3.8 (95\% CI:1.4, 10.5)), Extrapulmonary tuberculosis (AHR = 2.9 (95\% CI: 1.1, 7.6)), advanced WHOstaging(III\&IV) (AHR=6.8 (95\% CI: 1.9, 24.9)) and hemoglobin level $<10 \mathrm{mg} / \mathrm{dl}$ during follow-up (AHR 3.75 (95\% CI: 1.06, 13.28)) were predictors of increased mortality.

Conclusion: The mortality rate of children co-infected with TB and HIV was high. Early diagnosis and treatment of TB among HIV-infected children is needed. The treatment of malnutrition and anemia should be given emphasis. Strengthening the administration of preventive therapy (IPT, CPT) and counseling on adherence to ART drugs were crucial interventions to reduce mortality among children co-infected with TB and HIV. Children who have extra-pulmonary tuberculosis and advanced clinical staging (III and IV) need special consideration during treatment.

Keyword: Predictors of mortality; Co-infection with TB and HIV; Children; Retrospective follow-up study 


\section{Background}

Tuberculosis (TB) and human immunodeficiency virus (HIV) co-infection remain a major global and national health problem that requires substantial action to achieve the Sustainable Development Goals (SDG) and the END-TB strategies [1]. Both TB and HIV are the leading causes of death from infectious diseases worldwide [2]. Mycobacterium tuberculosis and HIV co-infection in the human body, potentiate each other and accelerate to death by deteriorating body immunity causing premature death if untreated [3]. Tuberculosis is a major cause of morbidity and mortality in HIV-infected children [4]. In 2015, the World Health Organization (WHO) report showed that nearly 41,000 children died from TB and HIV co-infection. Of which more than $83 \%$ were occurred in Africa [5]. Mortality among children co-infected with TB and HIV varied in different settings and fluctuated widely from $6.2 \%$ to $36.5 \%$ [5-7]. In Ethiopia, mortality of children co-infected with TB and HIV was $14 \%$ [8] and co-infected children had six times greater death than TB disease alone [9]. Furthermore, more than 1 in 5 TB and HIV coinfected individuals were died [10], but this huge problem was not specifically known in children.

The prevalence of TB and HIV co-infection in children was under-assured due to the problem of reaching a definitive diagnosis. However, the WHO report showed that HIV prevalence among children with active TB disease ranges from 10 to $60 \%$, depending on the background rates of HIV infection in countries with moderate to high prevalence of TB [11]. The estimated rates of tuberculosis among HIV positive children also had a wide variation, depending on the TB epidemic and the coverage of highly active antiretroviral treatment (HAART) coverage in the area [4].

Data on the survival of TB and HIV co-infection in children are still lacking and the available information is difficult to interpret due to problems with the diagnosis and selection of study populations [4]. In developing countries, including Ethiopia, the management of TB and HIV co-infection in children is very challenging due to the inaccessibility of appropriate formulations of drugs, drug-drug interactions, pill burdens, drug side effects, and poor drug adherence [12-14]. This may result in high TB incidence and mortality among HIV-positive children. TB is not only the most commonly reported opportunistic infection [15], but also a major cause of hospital admission and death in HIV infected children [16]. The cause of death is also multifactorial and determined by socio demographic, clinical, laboratory, drug and follow-up related factors [8]. Which are poorly understood. Therefore, studies on mortality and its predictors in TB and HIV co-infection in children are very significant to designate appropriate action according to their ages.
Most of the studies on TB-HIV co-infection focused on adult, fewer studies on general co-infected population, little is known in pediatrics sub-age group. Still, the problem in children is masked and actions are taken based on findings from studies in the adult population. However, the problem is very alarming in children due to immature immune system and fast deterioration into death $[17,18]$. A previous study in the comprehensive specialized hospital of Gondar University in Ethiopia lacks a time specification on the TB and HIV co-infection period, rather they prolonged their follow-up after TB was cured. This makes the study more biased.

To some extent, there is better evidence on the incidence and predictors of tuberculosis in HIV-infected children [19,20], but evidence on survival and mortality after co-infection is limited in Ethiopia. Therefore, survival and predictors of mortality among children co-infected with TB and HIV have not been well documented in Ethiopia. Therefore, this study was to try to fill the above gaps by estimating survival and identifying predictors of mortality among children co-infected with TB / HIV in public general hospitals in Mekelle and the southern zone of Tigray region, northern Ethiopia.

\section{Methods}

\section{Study Design, Setting, and Period}

A retrospective hospital follow-up study was conducted in two zones of the Tigray Region (Mekelle and Southern), which is located in the northern part of Ethiopia by reviewing 10 years (20082018) medical records of children co-infected with TB and HIV in 2019. About $1,179,687$ populations lived in these two zones. Of which 515,524 were children [21]. The study was conducted from October 1,2018 to June 30, 2019 in three selected general hospitals (Mekelle, Alamata, and Maychew).

\section{Population and Sampling}

\section{Source Population}

All children infected with TB and HIV co-infected under 15 years of age who received follow-up care from January 1 / 2008 to December 30/2018 in the ant-retroviral treatment (ART) clinic at public general hospitals of the Mekelle and southern zone of the Tigray region, North Ethiopia.

\section{Study Population}

All children co-infected with TB and HIV, under 15 years of age and those who followed up from January 1 / 2008 to December $30 / 2018$ in the ART care clinic of selected hospitals in the study area. 


\section{Inclusion and Exclusion Criteria}

Children infected with TB-HIV co-infected younger than 15 years were included in this study and had follow-up care from January 1/2008 - December 30/2018 in a selected hospital. Children who had missed key information on clinical, immunological, drug information and their outcomes had not been recorded on medical charts were excluded.

\section{Sampling Technique}

In the Mekelle and Sothern zones of the Tigray region, five general hospitals were found to provide ART services. These are the general hospitals of Mekelle, Quiha, Maychew, Alamata, and Korem. However, this study used cluster sampling by randomly selecting three hospitals (Mekelle, Alamata, and Maychew). Since we used cluster sampling, all children co-infected with TB and HIV who were enrolled in selected hospitals in two zones who met the inclusion criteria were included. The medical charts of children with TB and HIV co-infected from 2008 -2018 were reviewed.

\section{Data Collection and Analysis}

Data were collected from medical records (charts) using a data extraction checklist developed from the national HIV intake and follow-up form [22]. The checklist consisted of sociodemographic, clinical, and HIV care/ART/ follow-up related information. Data were collected from April 15/2019 to May 20/2019 from medical records. If the child is co-infected with TB and HIV, the follow-up should continue for the entire life (for HIV care) even if the child was cured from TB. After verifying completeness and consistency, the data were coded and entered into Epi-data manager version 4.4.2.1 and then exported to Stata version 14 for analysis. Kaplan-Meier survival graph and Log-rank test were used to compare the survival difference between intragroups of categorical variables. Mortality rate, person-time observation, and mean survival time were calculated by Stata. The Cox proportional hazard model was used for analysis. The Schoenfeld residual test (estat phtest) or global test was used to check the Cox proportional hazard assumption, it was non-significant (Prob>chi2 $=0.4179$ ) indicates the hazard was proportional over time. Regarding multi- collinearity, the mean VIF was 1.39 indicates, collinearity between variables was within the acceptable range.

Both bivariate and multivariate analysis was computed to determine the association between predictor variables and the outcome variable. These variables that were significantly associated with a p-value of $<0.2$ in the bivariate analysis were entered into the multivariate analysis. Variables significantly associated with the outcome variable at a $p$-value $<0.05$ in the multivariate analysis were considered independent predictors of mortality. Finally, the adjusted hazard ratio with $95 \% \mathrm{CI}$ and P value was used to measure the significant association between predictors and outcome variable.

\section{Ethical Considerations}

The study protocol was evaluated and approved by the Institutional Review Board (IRB) of Mekelle University, a college of health sciences, and then ethical clearance was obtained. A cooperation letter was written to the chief executive managers of each hospital. Since the study was retrospective and document review, it did not cause any risk to the study participants.

\section{Results}

\section{Sociodemographic Characteristics}

A total of 282 children with co-infected TB and HIV were enrolled in the general hospitals of Mekelle, Alamata, and Maychew. Of which 29 were excluded from the study due to lost cards or incomplete data. The remaining 253 children co-infected with TB and HIV were included in the study. The median age of the study participants was 8 years with IQR (4-13). One hundred and thirtyone $(51.8 \%)$ of the children were females (Table 1$)$.

Table 1: Sociodemographic characteristics of children co-infected with TB and HIV in general hospitals of two zones of the Tigray region, North Ethiopia, $2019(\mathrm{n}=253)$.

\begin{tabular}{|c|c|c|c|c|}
\hline \multicolumn{2}{|c|}{ Characteristics } & Total N (\%) & Death N (\%) & Censored N (\%) \\
\cline { 3 - 5 } & n=253 & n=38 & $17(6.7)$ & $105(41.5)$ \\
\hline \multirow{2}{*}{ Sex of the child } & Male & $122(48.2)$ & $21(8.3)$ & $110(43.5)$ \\
\cline { 2 - 5 } & Female & $131(51.8)$ & $13(5.1)$ & $59(23.3)$ \\
\hline \multirow{3}{*}{ Age of the child } & $1-5$ & $72(28.6)$ & $9(3.6)$ & $60(23.7)$ \\
\cline { 2 - 5 } & $5-10$ & $69(27.3)$ & $9(3.6)$ & $60(23.7)$ \\
\cline { 2 - 5 } & $10-15$ & $69(27.3)$ & $7(2.8)$ & $36(14.2)$ \\
\hline \multirow{2}{*}{ Residence of the child } & $15-18$ & $43(17)$ & $28(11.1)$ & $158(62.5)$ \\
\cline { 2 - 5 } & Urban & $186(73.6)$ & $10(4.0)$ & $57(22.5)$ \\
\hline
\end{tabular}




\begin{tabular}{|c|c|c|c|c|}
\hline \multirow{4}{*}{ The child lives with } & the parent's & $107(81.8)$ & $32(12.6)$ & $175(69.2)$ \\
\hline & Grandparents & $33(13.1)$ & $4(1.6)$ & $29(11.5)$ \\
\hline & Siblings & $8(3.2)$ & $1(0.4)$ & $7(2.8)$ \\
\hline & Others & $5(2)$ & $1(0.4)$ & $4(1.6)$ \\
\hline \multirow{2}{*}{ Sex of the care giver's } & Male & $51(19)$ & $11(4.3)$ & $40(15.8)$ \\
\hline & Female & 202(79.9) & $27(10.7)$ & $175(69.2)$ \\
\hline \multirow{4}{*}{ Age of care giver's } & $15-24$ & $17(6.7)$ & $3(1.2)$ & $14(5.5)$ \\
\hline & $25-34$ & $100(39.5)$ & $18(7.1)$ & $82(32.4)$ \\
\hline & $35-44$ & $84(32.9)$ & $10(4.0)$ & $73(28.9)$ \\
\hline & $>=45$ & $53(21)$ & $7(2.8)$ & $46(18.2)$ \\
\hline \multirow{3}{*}{$\begin{array}{l}\text { Occupation of the care } \\
\text { giver's }\end{array}$} & Housewife & $122(42.8)$ & $15(5.9)$ & $107(42.3)$ \\
\hline & Government employer & $51(20.1)$ & $11(4.3)$ & $40(15.8)$ \\
\hline & Private worker & $80(31.6)$ & $12(4.7)$ & $68(26.9)$ \\
\hline \multirow{4}{*}{$\begin{array}{l}\text { Educational Level of the } \\
\text { care giver's }\end{array}$} & Illiterate & $86(34)$ & $9(3.6)$ & $77(30.4)$ \\
\hline & Primary school & $59(23.4)$ & $10(4.0)$ & $49(19.4)$ \\
\hline & Secondary school & $47(18.6)$ & $5(2.0)$ & $42(16.6)$ \\
\hline & College or University & $61(24.1)$ & $14(5.5)$ & $47(18.6)$ \\
\hline
\end{tabular}

\section{Clinical and Immunological Related Characteristics}

Of a total of 253 children co-infected with TB and HIV, 186 (73.6\%) of them developed TB after starting ART. At baseline, 165 (65.2\%) of the children co-infected with TB and HIV had WHO stage III, and 129 (51\%) had a CD4 count of less than 350 with a median of 330 cells (IQR (176.50-519.50)) cells/ $\mu$ l. During follow- up, 145 (57.3\%) of the children co-infected with TB and HIV had improved their WHO staging to stage I \& II. However, 66 (26.2\%) of the children had a CD4 count of less than 350 with a median of 540 IQR cells (322.50-840.50) cells/ $\mu$ l. Thirteen (5.2\%) of the children had anemia (HGB $<10 \mathrm{mg} / \mathrm{dl}$ ) with a median HGB level of 13 (IQR (12-14.4)) mg/dl (Table 2).

Table 2: Clinical and immunological characteristics among children co-infected with TB and HIV in general hospitals of two zones of the Tigray region, North Ethiopia, 2019 ( $\mathrm{n}=253)$.

\begin{tabular}{|c|c|c|c|c|}
\hline \multirow{2}{*}{\multicolumn{2}{|c|}{ Characteristics }} & \multirow{3}{*}{$\begin{array}{c}\text { Total N (\%) } \\
\mathbf{n}=\mathbf{2 5 3} \\
165(65.2)\end{array}$} & \multirow{2}{*}{$\begin{array}{c}\text { Death N \%) } \\
\mathrm{n}=38\end{array}$} & \multirow{3}{*}{$\begin{array}{c}\text { Censored N (\%) } \\
\mathbf{n}=\mathbf{2 1 5} \\
147(58.1)\end{array}$} \\
\hline & & & & \\
\hline \multirow{2}{*}{ Baseline WHO staging } & Stage III & & 18(7.1) & \\
\hline & Stage IV & $88(34.8)$ & $20(7.9)$ & $68(26.9)$ \\
\hline \multirow{2}{*}{$\begin{array}{l}\text { WHO Staging- during } \\
\text { follow-up }\end{array}$} & Stage I \&II & $145(57.3)$ & $6(2.4)$ & $139(54.9)$ \\
\hline & Stage III \&IV & $108(42.6)$ & $32(12.6)$ & $76(30.0)$ \\
\hline \multirow{2}{*}{ Baseline HGB } & $<10$ & $47(18.6)$ & $17(6.7)$ & $30(11.9)$ \\
\hline & $>=10$ & $206(81.4)$ & $21(8.3)$ & 185(73.1) \\
\hline \multirow{2}{*}{ HGB level during-follow-up } & $<10$ & $13(5.2)$ & $7(2.8)$ & $6(2.4)$ \\
\hline & $>=10$ & $240(94.8)$ & $31(12.3)$ & $209(82.6)$ \\
\hline \multirow{4}{*}{ Weight for age at baseline } & Greater than 1 & $78(30.8)$ & $3(1.2)$ & $75(29.6)$ \\
\hline & Between $-1 \& 1$ & $65(25.7)$ & $8(3.2)$ & $57(22.5)$ \\
\hline & Between -2 \&-1 & $60(23.8)$ & $9(3.6)$ & $51(20.2)$ \\
\hline & Less than -2 & $50(19.8)$ & $18(7.2)$ & $32(12.6)$ \\
\hline \multirow{6}{*}{ Under-nutrition at baseline } & No & $166(65.6)$ & $11(4.3)$ & $155(61.3)$ \\
\hline & Yes & $87(35.4)$ & $27(10.7)$ & $60(23.7)$ \\
\hline & Under-weight & $29(11.5)$ & $6(2.4)$ & $23(9.1)$ \\
\hline & Sever-underweight & $36(14.2)$ & $14(5.5)$ & $22(8.7)$ \\
\hline & Moderate wasting & $7(2.8)$ & $4(1.6)$ & $3(1.2)$ \\
\hline & Sever wasting & $23(9)$ & $13(5.2)$ & $10(3.8)$ \\
\hline
\end{tabular}




\begin{tabular}{|c|c|c|c|c|}
\hline & Moderate stunting & $6(2.4)$ & 0 & $6(2.4)$ \\
\hline & Severe stunting & $10(4)$ & $3(1.2)$ & $7(2.8)$ \\
\hline & Malnutrition was treated & $83(32.8)$ & $27(10.7)$ & $56(22.1)$ \\
\hline \multirow{3}{*}{ Past TB treatment history } & No & $219(86.4)$ & $26(10.3)$ & $193(76.3)$ \\
\hline & Yes & $34(13.4)$ & $12(4.7)$ & $22(8.7)$ \\
\hline & $\begin{array}{l}\text { Past TB treatment was } \\
\text { completed }\end{array}$ & $31(12.3)$ & $12(4.8)$ & $19(7.5)$ \\
\hline \multirow{2}{*}{ History of OI } & No & $145(57.4)$ & $8(3.2)$ & $137(54.2)$ \\
\hline & Yes & $108(42.7)$ & $30(11.9)$ & $78(30.8)$ \\
\hline \multirow{2}{*}{ HIV confirmed } & Before TB & $184(72.8)$ & $30(11.9)$ & $154(60.9)$ \\
\hline & after TB & $69(27.2)$ & $8(3.2)$ & $61(24.1)$ \\
\hline \multirow{4}{*}{$\begin{array}{l}\text { Weight for age during- } \\
\text { follow-up }\end{array}$} & Greater than 1 & $105(41.5)$ & $5(2.0)$ & $100(39.5)$ \\
\hline & Between $-1 \& 1$ & $100(39.5)$ & $19(7.5)$ & $81(32.0)$ \\
\hline & Between -2 \&-1 & $35(13.9)$ & $9(3.6)$ & $26(10.3)$ \\
\hline & Less than -2 & $13(5.1)$ & $5(2.0)$ & $8(3.2)$ \\
\hline \multirow{2}{*}{$\begin{array}{l}\text { OIS other than TB during } \\
\text { the follow-up time }\end{array}$} & No & 197(78.9) & $23(9.1)$ & $174(68.8)$ \\
\hline & Yes & $56(22.1)$ & $15(5.9)$ & $41(16.2)$ \\
\hline \multirow{2}{*}{ Type of TB } & PTB & 193(76.2) & 20(7.9) & $173(68.4)$ \\
\hline & ЕРТВ & $60(23.8)$ & $18(7.1)$ & $42(16.6)$ \\
\hline \multirow{2}{*}{ Time of TB occurrence } & Pre ART & $67(26.4)$ & $9(3.6)$ & $58(22.9)$ \\
\hline & During ART & $186(73.6)$ & $29(11.5)$ & $157(62.1)$ \\
\hline
\end{tabular}

\section{Education and Follow-Up Related Characteristics}

One hundred and ninety-seven (77.9\%) of the respondents had taken co-trimoxazole preventive therapy and 145 (57.3\%) had also taken isoniazid preventive therapy before developing TB. The initial ART regimen was changed in 59 (23.3\%) of the children due to side effects 35 (13.9\%), ТВ 9 (3.6\%), treatment failure 13 $(5.1 \%)$ and other reasons $4(1.6 \%)$ such as drug toxicity. Firstline ART treatment failure was observed in 13 (5.1\%) children. Of these, 10 (76.9\%) of them initiated second-line ART regimens. Regarding ART adherence, 211 (88.4\%) of the children had good ART adherence (Table 3).

Table 3: Medication and follow-up related characteristics among children co-infected with TB and HIV in general hospitals of two zones of the Tigray region, North Ethiopia, $2019(\mathrm{n}=253)$.

\begin{tabular}{|c|c|c|c|c|}
\hline \multirow{2}{*}{\multicolumn{2}{|c|}{ Characteristics }} & \multirow{3}{*}{$\begin{array}{c}\text { Total N (\%) } \\
\mathbf{n}=\mathbf{2 5 3} \\
108(42.7)\end{array}$} & \multirow{3}{*}{$\begin{array}{c}\text { Death N (\%) } \\
=38 \\
26(10.3)\end{array}$} & \multirow{3}{*}{$\begin{array}{c}\text { Censored N (\%) } \\
\mathbf{n}=\mathbf{2 1 5} \\
82(32.4)\end{array}$} \\
\hline & & & & \\
\hline \multirow{2}{*}{ Taken INH at baseline } & No & & & \\
\hline & Yes & $145(57.3)$ & $12(4.7)$ & $133(52.6)$ \\
\hline \multirow{2}{*}{ Taken CPT at baseline } & No & $56(22.1)$ & $13(5.1)$ & $43(17.0)$ \\
\hline & Yes & $197(77.9)$ & $25(9.9)$ & $172(68.0)$ \\
\hline \multirow{6}{*}{ First-line treatment failure } & No & $240(94.9)$ & $29(11.5)$ & $211(83.4)$ \\
\hline & Yes & $13(5.1)$ & $9(3.6)$ & $4(1.6)$ \\
\hline & Immunological failure & $11(4.4)$ & $8(3.2)$ & $3(1.2)$ \\
\hline & Virological failure & $5(2)$ & $2(0.8)$ & $3(1.2)$ \\
\hline & Clinical failure & $9(3.6)$ & $7(2.8)$ & $2(0.8)$ \\
\hline & $\begin{array}{c}\text { The second-line regimen } \\
\text { was started }\end{array}$ & $10(3.9)$ & $6(2.4)$ & $4(1.6)$ \\
\hline \multirow{3}{*}{ Child HIV disclosure status } & fully disclosed & $99(39.1)$ & $18(7.1)$ & $81(31)$ \\
\hline & partially disclosed & $67(26.5)$ & $9(3.6)$ & $58(22.9)$ \\
\hline & not disclosed & $87(34.3)$ & $11(4.3)$ & $76(30.0)$ \\
\hline
\end{tabular}




\begin{tabular}{|c|c|c|c|}
\hline \multirow{4}{*}{\begin{tabular}{c}
$*$ \\
\multirow{2}{*}{ Eligibility criteria }
\end{tabular}} & Age & $21(8.3)$ & $3(1.2)$ \\
\cline { 2 - 4 } & CD4 count & $7(2.8)$ & $4(1.6)$ \\
\cline { 2 - 4 } & WHO staging & $97(38.8)$ & $9(3.6)$ \\
\cline { 2 - 4 } & both CD4 and WHO staging & $127(50.2)$ & $22(8.7)$ \\
\hline \multirow{2}{*}{$\begin{array}{c}\text { Taken CPT during the } \\
\text { follow-up time }\end{array}$} & No & $25(9.9)$ & $1(35.2)$ \\
\cline { 2 - 4 } Child's ART adherence & Good & $218(90.1)$ & $37(14.6)$ \\
\cline { 2 - 4 } & Poor & $211(88.4)$ & $14(5.5)$ \\
\hline
\end{tabular}

The Mortality Rate Among Children Co-Infected with TB and HIV

Of a total of 253 children co-infected with TB and HIV included in the study, 38 (15\%) deaths and 215 (85\%) censored were recorded. Of the censored cases, 186 (73.5\%) were alive until the end of the follow-up period, 14 (5.5\%) were transferred out, 15 (5.9\%) were dropped out of follow-up, and the rest were in TB treatment. Those 253 TB and HIV co-infected children were followed for different periods ( 1 month to 12 months), which provides 226 child-month observations with a mean survival time of 10.75 (95\% CI; 10.37 -11.14) months. In this study, the mortality rate was 0.17 (95\% CI 0.12 to 0.23 ) per 1,000 child-month observations. The majority (73.7\%) of the deaths occurred in the first six months of followup period and 15 (40\%) occurred during the initial phase of TB treatment. All deaths 38 (15.02\%) had occurred during ART. The cumulative probability of survival at the end of 2 months, 6 months, 9 months and 12 months was $94.0 \%, 88.0 \%, 85.0 \%$ and $82.9 \%$, respectively (Figure 1).

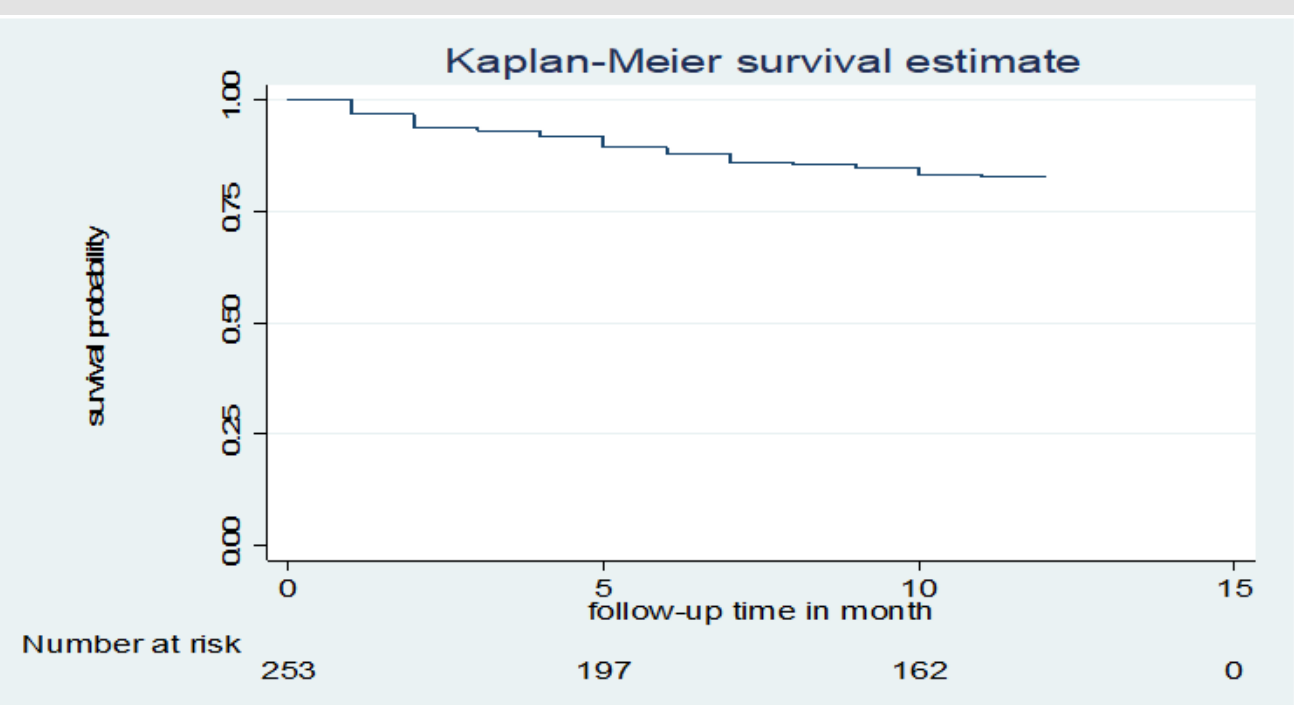

Figure 1: Kaplan-Meier cumulative survival estimate of children co-infected with TB and HIV in general hospitals of two zones of the Tigray region, North Ethiopia, 2019.

\section{Predictors of Mortality Among Children Co-Infected with TB and HIV}

Bivariate and multivariate analyzes were used to assess the significant association between exposure variables and the outcome variable. Underweight at baseline, moderate / severe wasting at baseline, IPT, CPT, baseline hemoglobin level, level of adherence to ART, type of tuberculosis, WHO staging during follow-up, and hemoglobin level during follow-up were statistically significant at 0.2 level of significance in bivariate analysis. In multivariate analysis; underweight at baseline, IPT user/not/, ART adherence level, type of TB, WHO staging during follow-up, and hemoglobin level during follow-up were statistically significant at 0.05 significance level (Table 4).

The risk of death among children with TB and HIV co-infected with underweight was approximately 8 times higher than children with normal weight at baseline (AHR=7.9 (95\% CI 1.26, 49.3)). Children who did not take IPT were approximately 4 times more likely to experience death than children who had taken IPT 
(AHR=3.69 $(95 \% \mathrm{CI}=1.26,10.8))$. The risk of child death with poor adherence to ART was approximately 4 times higher than children with good adherence to ART (AHR = 3.82 (95\% CI: 1.38, 10.54)). The risk of death among children infected with extrapulmonary TB was also approximately 3 times higher than infected children with pulmonary $\mathrm{TB}(\mathrm{AHR}=2.9$ (95\% CI: 1.1, 7.6)). During follow-up, children with advanced WHO staging (III \& IV) were approximately 7 times higher risk of death than children with stage I and II (AHR=6.79 (95\% CI= 1.85, 24.9)). Anemic children were approximately four times more likely to experience death compared to nonanemic children during follow-up (AHR=3.76 (95\% CI= 1.06, 13.27)).

Table 4: Results of the bivariate and multivariate analysis among children infected with TB and HIV in general hospitals of two zones of the Tigray region, North Ethiopia, 2019(n=253).

\begin{tabular}{|c|c|c|c|c|c|}
\hline \multicolumn{2}{|c|}{ Characteristics } & \multirow{2}{*}{$\begin{array}{c}\text { Death } \\
26 \\
\end{array}$} & \multirow{2}{*}{$\begin{array}{c}\text { Censored } \\
82 \\
\end{array}$} & \multirow{2}{*}{$\begin{array}{c}\text { CHR }(\mathbf{9 5} \% \mathbf{C I}) \\
3.66(1.83-7.30) \\
\end{array}$} & \multirow{2}{*}{$\begin{array}{c}\text { AHR (95\% CI) } \\
3.68(1.26-10.7)^{* *}\end{array}$} \\
\hline Taken INH at haceline & No & & & & \\
\hline (20) & Yes & 12 & 133 & 1.00 & 1.00 \\
\hline \multirow{2}{*}{ Taken CPT at baseline } & No & 13 & 43 & $2.33(1.18-4.60)$ & $1.77(0.73-5.30)$ \\
\hline & Yes & 25 & 172 & 1.00 & 1.00 \\
\hline \multirow{2}{*}{$\begin{array}{l}\text { WHO Staging- during } \\
\text { our follow-up }\end{array}$} & Stage I \&II & 6 & 139 & 1.00 & 1.00 \\
\hline & III \&IV & 32 & 76 & $8.64(3.59-20.77)$ & $6.79(1.85-24.65)^{* *}$ \\
\hline \multirow{2}{*}{ HGB level at Baseline } & $<10$ & 17 & 30 & $4.49(2.34-8.61)$ & $0.44(0.12-1.56)$ \\
\hline & $>=10$ & 21 & 185 & 1.00 & 1.00 \\
\hline \multirow{2}{*}{$\begin{array}{l}\text { HGB level during our } \\
\text { follow-up }\end{array}$} & $<10$ & 7 & 6 & $7.89(3.30-18.86)$ & $3.75(1.06-13.28)^{* *}$ \\
\hline & $>=10$ & 31 & 209 & 1.00 & 1.00 \\
\hline \multirow{4}{*}{$\begin{array}{l}\text { Weight for age at } \\
\text { baseline }\end{array}$} & $>1$ & 3 & 75 & 1.00 & 1.00 \\
\hline & $\mathrm{B} / \mathrm{n}-1 \& 1$ & 8 & 57 & $3.74(0.98-14.16)$ & $3.59(0.6-21.41)$ \\
\hline & $\mathrm{B} / \mathrm{n}-2 \&-1$ & 9 & 51 & $4.39(1.18-16.31)$ & $1.84(0.29-11.86)$ \\
\hline & $<=-2$ & 18 & 32 & $12.15(3.55-41.58)$ & $7.86(1.25-49.2)^{* *}$ \\
\hline \multirow{2}{*}{$\begin{array}{l}\text { Moderate / severe } \\
\text { wasting at baseline }\end{array}$} & No & 22 & 202 & 1.00 & 1.00 \\
\hline & Yes & 16 & 13 & $7.69(4.01-14.74)$ & $2.54(0.60-10.78)^{*}$ \\
\hline \multirow{2}{*}{ Child's ART adherence } & Good & 14 & 197 & 1.00 & 1.00 \\
\hline & Poor & 24 & 18 & $20.32(10.13-40.75)$ & $3.82(1.38-10.5)^{* *}$ \\
\hline \multirow{2}{*}{ Type of TB } & РТВ & 20 & 173 & 1.00 & 1.00 \\
\hline & ЕРТВ & 18 & 42 & $3.06(1.60-5.84)$ & $2.87(1.08-7.58)^{* *}$ \\
\hline
\end{tabular}

\section{Discussion}

The study provides information on the overwhelming problem of high mortality and associated predictors among children with TB and HIV coinfected. The mortality rate in this study was 0.17 (95\% CI 0.12-0.23) per 1000 child-month observations. The result was lower than the mortality rate reported from a single study conducted in four developing countries (Burkina Faso, Cambodia, Cameroon and Vietnam), which is 0.370 per 1000 child- month observations [23]. The difference may depend on the sample size difference used by the studies.

In this study, mortality was higher in underweight children at baseline. A similar finding was reported from a study conducted in Thailand [24]. This might be the effect of underweight on reducing body metabolic processes resulting in inadequate energy acquisition that increases disease progression, which may end up in death. Furthermore, inadequate weight gain in TB treatment indicates a poor response to treatment [25]. However, stunting and wasting were not significant in this study. This could be due to a higher proportion $(90 \%)$ of children diagnosed with malnutrition in this study who received treatment for malnutrition. The study also revealed that children who did not take IPT were three times more likely to experience death than children who did take IPT. This was in line with a study conducted in Gondar, Ethiopia [8]. The possible reason might be that IPT reduces the severity and spread of TB disease. However, CPT was not found to be statistically significant in this study, which was reported as a protective factor for death in a study conducted in Gondar, Ethiopia [8]. This may be because a higher proportion (78\%) of our respondents had taken CPT and were unable to make a difference. The number of children who didn't take CPT and died was too few (5.1\%). For better survival, HIV positive children should take both CPT and IPT as preventive prophylaxis. In this study, the risk of death among children infected with extrapulmonary TB was three times higher than that of children infected with pulmonary TB. This result was in line with a study conducted in Gondar, Ethiopia [8]. The reason 
might be that the easy diagnostic technique for EPTB is not available in most of our clinical settings, resulting in delayed initiation of anti-TB treatment leading to rapid disease progression and easy involvement of vital organs.

During follow-up, this study revealed that anemia was associated with higher child death. No previous studies examined anemia during follow-up, but at the beginning of the study, it was identified as a predictor of mortality in studies conducted in Gondar (Ethiopia) and Thailand [8-24]. Higher mortality with anemia may be associated with decreased oxygen and nutrient care capacity of the blood, resulting in inadequate oxygen and nutrient supply to vital organs that become synergistic with TB and HIV [8]. In contrast to other studies in Gondar (Ethiopia) [8], Thailand [24], Nigeria [6], Malawi [26], and a single study in four developing countries [23]; WHO staging, CD4 count, and hemoglobin level at baseline were not significantly associated with mortality in this study. The reason might be that unlike these studies, our study assessed the effect of the variables during follow-up time and at baseline. Most of these variables were significantly associated during follow-up, which shows a better effect on the outcome variable than at baseline. This is one of the strengths of this study. Assessing the effect of these variables during follow-up enables us to overlook the more accurate effects of exposure variables on the outcome variable. The study also considered the time of the event, which enables us to consider the contribution of censored cases.

\section{Limitation of the Study}

Since the study was a retrospective review of the chart (secondary data), some variables not documented in the child's medical records were missed. A further prospective study is needed to address other important issues not addressed by this study.

\section{Conclusion}

The mortality rate of children co-infected with TB and HIV in two zones of the Tigray region was high. Most deaths occurred within the first six months of the follow-up period. Underweight at baseline, IPT non-user, poor ART adherence, extrapulmonary TB, advanced WHO staging during follow-up, advanced/severe immunosuppression status during follow-up, and hemoglobin level $<10 \mathrm{mg} /$ dl during follow-up were predictors of increased mortality. This study is important for planning and decision making by pointing out gaps to make a successful strategy to combat TB and HIV and related consequences to increase the overall effectiveness of therapy in TB and HIV co-infected infected children.

\section{Declaration}

\section{Ethical Approval and Consent to Participate}

Ethical approval was obtained from the Institutional Review Board of the College of Health Sciences, Mekelle University. A letter of cooperation from the School of Nursing and a permission letter from hospitals were also secured before data collection. The name of the respondent was not mentioned during data collection.

\section{Availability of Data and Materials}

The data set analyzed during the current study is available from the cross-pondering author on reasonable request.

\section{Acknowledgment}

We greatly acknowledge and appreciate data collectors, hospital staff, hospital administrators, and Tigray Regional Health Bureau; without them, this work cannot be real. We also acknowledge the School of Nursing College Health Sciences, Mekelle University, for their financial and technical support.

\section{Authors' Contributions}

JN conceived the study, designed, participated in data collection, performed data analysis, entered data, and interpreted the results. $\mathrm{MK}, \mathrm{GH}, \mathrm{HH}$, and BG participated in the data analysis and wrote the article. All authors approved the final draft of the manuscript.

\section{References}

1. (2015) Organization WH: Implementing the end TB strategy: the essentials. In: World Health Organization.

2. Adejumo OA, Daniel OJ, Adebayo BI, Adejumo EN, Jaiyesimi EO, et al. (2015) Treatment outcomes of childhood TB in Lagos, Nigeria. Journal of tropical pediatrics 62(2): 131-138.

3. Bruchfeld J, Correia Neves M, Källenius G (2015) Tuberculosis and HIV coinfection. Cold Spring Harbor perspectives in medicine 5(7): a017871.

4. Venturini E, Turkova A, Chiappini E, Galli L, de Martino M, et al. (2014) Tuberculosis and HIV co-infection in children. BMC infectious diseases 14(1): S5.

5. (2015) Organization WH: Global tuberculosis report 2015: World Health Organization.

6. Ebonyi AO, Oguche S, Agbaji OO, Sagay AS, Okonkwo PI, et al. (2016) Mortality among pulmonary tuberculosis and HIV-1 co-infected Nigerian children being treated for pulmonary tuberculosis and on antiretroviral therapy: a retrospective cohort study. Germs 6(4): 139-150.

7. Isaakidis P, Paryani R, Khan S, Mansoor H, Manglani M, et al. (2013) Poor outcomes in a cohort of HIV-infected adolescents undergoing treatment for multidrug-resistant tuberculosis in Mumbai, India. PLoS One 8(7): e68869.

8. Atalell KA, Birhan Tebeje N, Ekubagewargies DT (2018) Survival and predictors of mortality among children co-infected with tuberculosis and human immunodeficiency virus at University of Gondar Comprehensive Specialized Hospital, Northwest Ethiopia. A retrospective follow-up study. PloS one 13(5): e0197145.

9. Palme IB, Gudetta B, Bruchfeld J, Muhe L, Giesecke J (2002) Impact of human immunodeficiency virus 1 infection on clinical presentation, treatment outcome and survival in a cohort of Ethiopian children with tuberculosis. The Pediatric infectious disease journal 21(11): 10531061.

10. Abrha H, Tsehayneh B, Massa D, Tesfay A, Kahsay H (2015) Survival experience and its predictors among TB/HIV Co-infected patients in Southwest Ethiopia. Epidemiol (Sunnyvale) 5(2): 191. 
11. (2011) UNAIDs U, Organization WH: Global HIV/AIDS response: epidemic update and health sector progress towards universal access progress report 2011. Global HIV/AIDS response: epidemic update and health sector progress towards universal access: progress report 2011.

12. Pawlowski A, Jansson M, Sköld M, Rottenberg ME, Källenius G (2012) Tuberculosis and HIV co-infection. PLoS pathogens 8(2): e1002464.

13. Marais B, Graham S, Cotton M, Beyers N (2007) Diagnostic and management challenges for childhood tuberculosis in the era of HIV. The Journal of infectious diseases 196(1): S76-S85.

14. Marais B, Rabie H, Cotton M (2011) TB and HIV in children-advances in prevention and management. Paediatric respiratory reviews 12(1): 39-45.

15. Deribe A, Estifanos W (2018) Magnitude and determinants of opportunistic infections among Hiv/aids patients in Sphmmc, Addis Ababa, Ethiopia: Retrospective study. JOJ Pub Health 4(1).

16. Tilahun G, Gebre-Selassie S (2016) Treatment outcomes of childhood tuberculosis in Addis Ababa: a five-year retrospective analysis. BMC Public Health 16: 612.

17. Ugochukwu EF (2010) HIV/TB Co-infection in Nigerian children Nigerian Medical Journal 51(3): 120-124.

18. Newton SM, Brent AJ, Anderson S, Whittaker E, Kampmann B (2008) Paediatric tuberculosis. The Lancet infectious diseases 8(8): 498-510.

19. Ayalaw SG, Alene KA, Adane AA (2015) Incidence and predictors of tuberculosis among HIV positive children at University of Gondar Referral Hospital, northwest Ethiopia: a retrospective follow-up study. International scholarly research notices 2015: 307810.

\section{ISSN: 2574-1241}

\section{DOI: $10.26717 /$ BJSTR.2021.39.006252}

Jemberu Nigussie. Biomed J Sci \& Tech Res

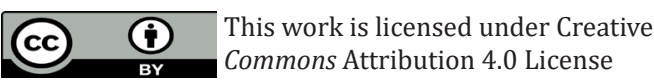

Submission Link: https://biomedres.us/submit-manuscript.php
20. Endalamaw A, Engeda EH, Tezera N (2018) Incidence of tuberculosis in children on antiretroviral therapy: a retrospective cohort study. BMC research notes 11(1): 745 .

21. (2019) Tigray regional health bureau: Demographic data of Tigray region and public health facilities, Ethiopia.

22. (2017) FMOH: Federal ministry of health Ethiopia National guidelines for comprehensive HIV prevention, care, and treatment. In. Addis Ababa, Ethiopia.

23. Marcy O, Tejiokem M, Msellati P, Huu KT, Do Chau V, et al. (2018) Mortality and its determinants in antiretroviral treatment-naive HIVinfected children with suspected tuberculosis: an observational cohort study. The Lancet HIV 5(2): e87-e95.

24. Salvadori N, Ngo Giang Huong N, Duclercq C, Kanjanavanit S, Ngampiyaskul C, et al. (2017) Incidence of tuberculosis and associated mortality in a cohort of human immunodeficiency virus-infected children initiating antiretroviral therapy. Journal of the Pediatric Infectious Diseases Society 6(2): 161-167.

25. Hicks R, Padayatchi N, Shah N, Wolf A, Werner L, et al. (2014) Malnutrition associated with unfavorable outcome and death among South African MDR-TB and HIV co-infected children. The International Journal of Tuberculosis and Lung Disease 18(9): 1074-1083.

26. Buck WC, Olson D, Kabue M, Ahmed S, Nchama L, et al. (2013) Risk factors for mortality in Malawian children with human immunodeficiency virus and tuberculosis co-infection. The International Journal of Tuberculosis and Lung Disease 17(11): 1389-1395.

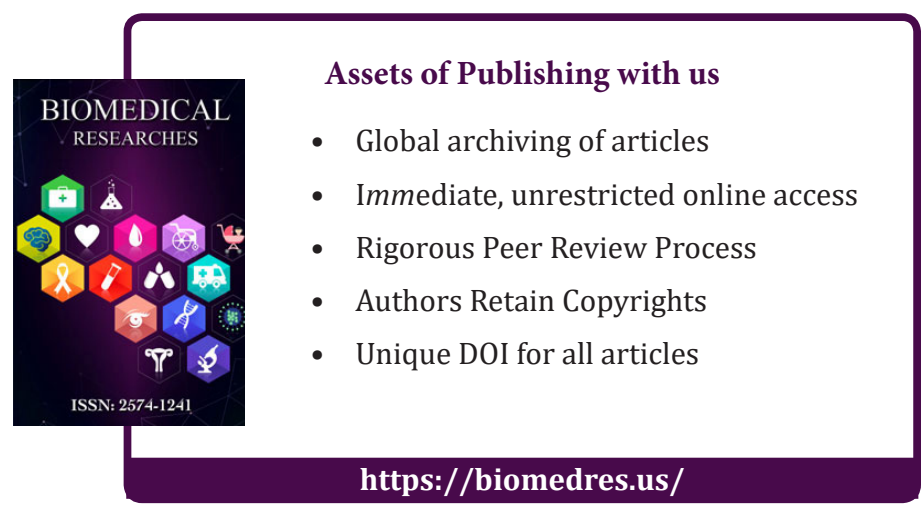

